Article

\title{
Laminaria digitata and Palmaria palmata Seaweeds as Natural Source of Catalysts for the Cycloaddition of $\mathrm{CO}_{2}$ to Epoxides
}

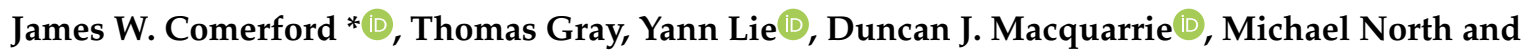 \\ Alessandro Pellis $\mathbb{D}$ \\ Green Chemistry Centre of Excellence, Department of Chemistry, University of York, York YO10 5DD, UK; \\ Thomas.Gray.1996@hotmail.com (T.G.); yl2864@york.ac.uk (Y.L.); duncan.macquarrie@york.ac.uk (D.J.M.); \\ michael.north@york.ac.uk (M.N.); ale.pellis@york.ac.uk (A.P.) \\ * Correspondence: james.comerford@york.ac.uk; Tel.: +44-1904-324547
}

Academic Editors: Robert Raja, Matthew E. Potter and Stephanie Chapman Received: 11 December 2018; Accepted: 9 January 2019; Published: 12 January 2019

\begin{abstract}
Seaweed powder has been found to act as an effective catalyst for the fixation of $\mathrm{CO}_{2}$ into epoxides to generate cyclic carbonates under solvent free conditions. Model background reactions were performed using metal halides and amino acids typically found in common seaweeds which showed potassium iodide (KI) to be the most active. The efficacy of the seaweed catalysts kelp (Laminaria digitata) and dulse (Palmaria palmata) was probed based on particle size, showing that kelp possessed greater catalytic ability, achieving a maximum conversion and selectivity of $63.7 \%$ to styrene carbonate using a kelp loading of $80 \%$ by weight with respect to epoxide, 40 bar of $\mathrm{CO}_{2}$, $120^{\circ} \mathrm{C}$ for $3 \mathrm{~h}$. Maximizing selectivity was difficult due to the generation of diol side product from residual $\mathrm{H}_{2} \mathrm{O}$ found in kelp, along with a chlorinated by-product thought to form due to a high quantity of chloride salts in the seaweeds. Data showed there was loss of organic matter upon use of the kelp catalyst, likely due to the breakdown of organic compounds and their subsequent removal during product extraction. This was highlighted as the likely cause of loss of catalytic activity upon reuse of the Kelp catalyst.
\end{abstract}

Keywords: $\mathrm{CO}_{2}$ sequestration; green catalyst; clean synthesis; sustainability

\section{Introduction}

An increase in net global $\mathrm{CO}_{2}$ emissions is expected to have significant consequences over the next few decades [1-5]. The majority of these emissions are a result of fossil fuel combustion for transportation and power generation, for domestic homes, industry, chemical processes (such as the Haber-Bosch) and production of meat [6-9]. A reduction in global $\mathrm{CO}_{2}$ emissions is paramount, however the complexity of this issue requires a holistic approach to tackle this significant problem. Whilst the production of chemicals from $\mathrm{CO}_{2}$ is not the answer alone, use of flue gas waste streams will allow the utilization of $\mathrm{CO}_{2}$ as a benign $\mathrm{C} 1$ feedstock to produce more sustainable chemical compounds. Production of five membered cyclic carbonates from the cycloaddition of $\mathrm{CO}_{2}$ to epoxides is one of the leading examples of this practice. The synthesis of ethylene and propylene carbonate [10] has received much attention in recent years due to their use as electrolytes in lithium ion batteries, the production of which has increased rapidly in parallel with increased production of electric cars. Furthermore, cyclic carbonates can be used in the synthesis of polymers [11-13], as intermediates in the production of dimethyl carbonate $[14,15]$ and even as green polar aprotic solvents aimed at replacing traditional solvents such as DMF, DMSO, NMP and acetonitrile [16,17]. There have been many different catalysts reported for this synthesis each with their individual benefits and drawbacks. 
Aluminum complexes reported by North [18] and Kleij [19] are extremely active in that they are able to catalyse the cycloaddition of $\mathrm{CO}_{2}$ under ambient temperatures and pressures. Although these reaction conditions are impressive, the multistep synthesis of the catalysts tend to have poor E-factors, leading to increased use of resources and energy, consequently increasing the carbon footprint for the process and overall environmental impact. Alternatively, metal halide salt catalysts tend to be much cheaper, but often use high temperatures and pressures of $>100^{\circ} \mathrm{C}$ and $20-60$ bar, often along with the necessitated addition of a hydroxyl containing co-catalyst to aid stabilization of the alkoxide intermediate and drive the reaction to high conversions. Interestingly, there have been a number of natural organic compounds reported as effective co-catalysts, such as cellulose [20], $\beta$-cyclodextrin [21], lecithin [22] and betaines [23]. Various amino acids have been reported as very effective co-catalysts, with histidine being one of the most active [24]. One of the most effective metal halide salts reported to date is potassium iodide (KI). Typically, this is produced from potassium hydroxide and iodide, where potassium is either mined from underground ore deposits, salt lakes or brines, and the iodide can be sourced from either caliche ore, brines or seaweeds (along with potassium salts), each often having direct environmental consequences [25-27]. Further to this, extraction, isolation, purification and transportation of such species require huge amounts of energy (the average mine consumes 25 $\mathrm{MW} / \mathrm{h}$ per tonne of material processed [28]), having an indirect environmental impact.

This paper details an investigation of the use of two different seaweeds as one-component, natural catalysts for the formation of cyclic carbonates due to the high quantities of metal halides found in the plant along with amino acids in the form of proteins. Direct use of the plant with minimal preparation has a significant number of benefits; the plant naturally sequesters inorganic minerals out of the sea removing the need for refining and purifying metal salts or halogens, seaweed is sustainable and extremely abundant, it is accessible and cheap throughout the world, along with the benefit of having reduced operator and environmental risk with regards to handling and manipulation. Kelp was chosen due to the well reported high concentrations of iodide and salts incorporated within the plant [29-31] and dulse was chosen as a comparison. Both contain amino acids, proteins and polysaccharides (such as cellulose, alginate, fucoidan and carrageenan) that could be beneficial to the synthesis [32]. Aside from being edible, both seaweeds already have industrial non-food applications with established harvesting and processing routes. They are commonly used as organic fertilizers and soil conditioners (both today and historically) [33], for the production of seaweed gums for use in the pharmaceutical, medical and cosmetics industries (extraction of alginates from Laminaria digitata, along with agar and carrageenan from Palmaria palmata) [34] as well as use in animal feed due to their protein content (up to $50 \%$ crude protein for red seaweeds and approximately $14 \%$ for the more easily harvested brown seaweeds) [35].

\section{Results and Discussion}

\subsection{Conversion to Styrene Carbonate Using Model Catalyst and Co-Catalyst}

Initially, a screen of different metal halides catalysts with different amino acid co-catalysts was performed as a baseline for comparison with the seaweed catalysts and also to identify any synergistic effect between the metal and amino acid co-catalyst. Full details of the procedures used are detailed in Experimental Section 4.3. Basic amino acids histidine and lysine were chosen for their reported ability to activate $\mathrm{CO}_{2}$ by formation of a carbamate salt [36], whereas glycine was chosen as a non-basic polar comparison, Table 1. Overall, the less electronegative potassium (K) salts were found to be more active than the sodium ( $\mathrm{Na}$ ) and calcium (Ca) equivalents. A small quantity of 1-phenyl-1,2-ethanediol by-product was observed, which was found to increase when incorporating polar amino acids histidine and lysine as co-catalysts, most likely due to residual water contamination, (SI, Table S1a-e). However, the addition of amino acid co-catalysts containing a basic group (histidine and lysine) significantly increased conversions to styrene carbonate for all metal halide catalysts containing a bromide and chloride counter ion; histidine was found to give the greatest synergistic effect of all, in accordance 
with the literature [37]. $\mathrm{CaCl}_{2}$ achieved $80.0 \%$ conversion to $2 \mathbf{a}$ when used with histidine as opposed to being inactive when used alone. However, a very different effect is observed for systems using an iodide counter ion, where for KI, introduction of an amino acid actually decreased conversions to carbonate. This may be due to increased interaction between either the metal cation and/or iodide anion with the amino acids and therefore reducing desired interaction with reagents, giving reduced conversions. An impressive synergistic effect is seen with $\mathrm{NaI}$ and glycine achieving a conversion of $97.1 \%$ as opposed to $23.1 \%$ using $\mathrm{NaI}$ or no conversion using glycine alone. The reason for this observation is unclear, however this may be attributed to the increased ability of glycine to aid the disassociation of the $\mathrm{NaI}$ ion pair. Comparatively, the chloride and bromide sodium salts appear to be less affected by the polarity of the amino acids possibly due to increased lattice energy and metal electronegativity. In these systems, the ability of the histidine to act as a catalyst alone (41.5\%) becomes much more important and has the dominant effect on total conversion to styrene carbonate.

Table 1. Conversion to styrene carbonate using different metal halides and amino acid co-catalysts.

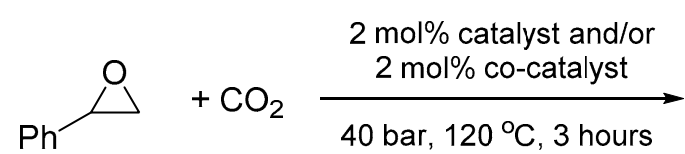

$1 a$

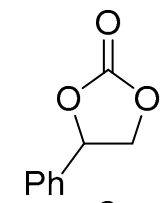

$2 a$

\begin{tabular}{|c|c|c|c|c|c|c|c|c|c|}
\hline \multirow{2}{*}{$\begin{array}{l}\text { Amino Acid } \\
\text { Co-catalyst }\end{array}$} & \multicolumn{8}{|c|}{ Conversion to 2a Using Metal Halide Catalyst ${ }^{1}$} & \multirow{2}{*}{$\begin{array}{c}\text { Basic } \\
\text { Sites }^{2}\end{array}$} \\
\hline & KI & $\mathrm{KBr}$ & $\mathrm{KCl}$ & $\mathrm{NaI}$ & $\mathrm{NaBr}$ & $\mathrm{NaCl}$ & $\mathrm{CaCl}_{2}$ & None & \\
\hline Histidine & 75.2 & 76.3 & 61.7 & 49.8 & 67.2 & 77.5 & 80.0 & 39.1 & $1\left(2^{\circ}\right)$ \\
\hline Lysine & 63.9 & 44.1 & 8.0 & 56.2 & 58.8 & 12.1 & 18.7 & 9.7 & $1\left(1^{\circ}\right)$ \\
\hline Glycine & 79.5 & 10.2 & 0.8 & 97.1 & 41.2 & 0.0 & 11.8 & 0.0 & 0 \\
\hline None & 100.0 & 0.9 & 1.0 & 23.1 & 2.8 & 1.0 & 0.0 & 0.0 & 0 \\
\hline
\end{tabular}

(1) $2 \mathrm{~mol} \%$ of metal halide catalyst and/or $2 \mathrm{~mol} \%$ of amino acid co-catalyst used in the synthesis. (2) $2^{\circ}$ refers to secondary amine, $1^{\circ}$ refers to primary amine.

The combination of various metal halides with amino acids has the potential to form very active catalytic systems. With the investigated metal halides likely to be present to some extent in seaweed, along with various amino acids side chains also being present in the form of proteins, two common seaweeds were investigated as catalysts for the synthesis of styrene carbonate.

\subsection{Kelp and Dulse as Catalysts}

A simple activity screen was performed in the first instance to identify if seaweed had catalytic potential. Kelp (Laminaria digitata, brown seaweed) and dulse (Palmaria palmata, red seaweed) were chosen for investigation due to the high concentrations of iodide previously reported for kelp and the excellent conversions obtained using iodide salts seen in the initial model screening. Both seaweeds were sourced from the North coast of Northern Ireland [38]. The kelp and dulse were blended and sieved prior to drying as detailed in Experimental Section 4.2, allowing us to maximise reproducibility of our investigations as well as understand the effect of particle size. Due to the many different organic and inorganic species likely to be contained within the seaweeds, a fixed $80 \%$ weight of seaweed catalyst relative to epoxide was used in the syntheses as detailed in Table 2. Reduced loading of the catalyst was found to also reduce conversions, (SI, Figure S1), whereas increased loading to $100 \%$ wt. caused issues with the reaction's optimal mass transfer. Conversions to carbonate did not appreciably increase when using pressures over 20 bar, however, 40 bar was used for all investigations to be comparable with the initial metal halide study, (SI, Table S2). Overall, kelp was found to be more active towards the formation of styrene carbonate than dulse, achieving a 29.9-33.2\% conversion to styrene carbonate in $3 \mathrm{~h}$ at $120^{\circ} \mathrm{C}$ and 40 bar $\mathrm{CO}_{2}$; however, some unexpected effects were observed. In contrast to the standard metal halide comparison shown in Table 1, there was a notable quantity of by-product formed by both of the seaweed catalysts. 
Table 2. Conversion to styrene carbonate using kelp and dulse of different particles sizes.

\begin{tabular}{ccccccccc}
\hline Seaweed & $\begin{array}{c}\text { Particle Size } \\
(\boldsymbol{\mu} \mathbf{m})\end{array}$ & $\begin{array}{c}\text { Carbonate } \\
\mathbf{2 a}(\mathbf{\%})\end{array}$ & $\begin{array}{c}\text { Diol 3a } \\
(\mathbf{\%})\end{array}$ & $\begin{array}{c}\mathbf{B A}^{\mathbf{1}} \mathbf{4 a} \\
\mathbf{( \% )}\end{array}$ & $\begin{array}{c}\mathbf{C P E}^{2} \mathbf{5 a} \\
\mathbf{( \% )}\end{array}$ & $\begin{array}{c}\mathbf{P A A}^{3} \mathbf{6 a} \\
\mathbf{( \% )}\end{array}$ & $\begin{array}{c}\text { Total } \\
\text { Conversion } \\
\text { from 1a (\%) }\end{array}$ & $\begin{array}{c}\text { Selectivity } \\
(\mathbf{\%})\end{array}$ \\
\hline \multirow{3}{*}{ Kelp } & $<125$ & 29.9 & 47.9 & 0.6 & 10.5 & 1.8 & 90.1 & 33.2 \\
& $125-300$ & 2.9 & 59.0 & 0.3 & 12.9 & 0.8 & 75.6 & 3.8 \\
& $300-500$ & 33.2 & 23.9 & 0.7 & 9.0 & 1.7 & 67.8 & 49.0 \\
\hline \multirow{3}{*}{ Dulse } & $<125$ & 19.4 & 26.4 & 0.4 & 5.2 & 0.8 & 52.2 & 37.2 \\
& $125-300$ & 4.3 & 25.1 & 0.4 & 4.9 & 0.6 & 34.8 & 12.3 \\
& $300-500$ & 16.2 & 14.0 & 0.5 & 4.4 & 1.0 & 35.5 & 45.7 \\
\hline
\end{tabular}

Aside from catalyst loading, reaction conditions used were identical to those used in Table 1, see Experimental Section 4.4. (1) BA-Benzaldehyde, (2) CPE-2-Chloro-1-phenylethanol, (3) PAA-Phenylacetaldehyde.

Although a certain quantity of diol by-product 3a was expected due to residual water, formation of 1-phenyl-2-chloroethanol (5a) was also found along with trace quantities of benzaldehyde (4a) and phenylacetaldehyde (6a) Scheme 1; Scheme 2. Formation of the chlorinated species $5 \mathbf{a}$ is most likely due to the relatively high concentrations of chloride salts found within the seaweeds. Although bromide and iodide anions are nucleophilic enough to ring open the epoxide, they are large soft nucleophiles and as such, able to act as good leaving groups upon attack from an activated $\mathrm{CO}_{2}$ carboxylate electron pair. The increased electronegativity of the chloride makes this a less good leaving group but a relatively good nucleophile and as such, forms a relatively stable chlorinated by-product. Formation of benzaldehyde $4 \mathbf{a}$ from diol by-product $3 \mathbf{a}$ has been well reported [39-41] however, due to the large quantity of potentially active catalytic species within this system; the exact route of formation was not identified. Interestingly, in order to preserve the benzylic carbon, formation of 6a suggests halide attack at the tertiary carbon, rather than at the less hindered secondary carbon.



Scheme 1. Formation of benzaldehyde, chloro and diol by-products.

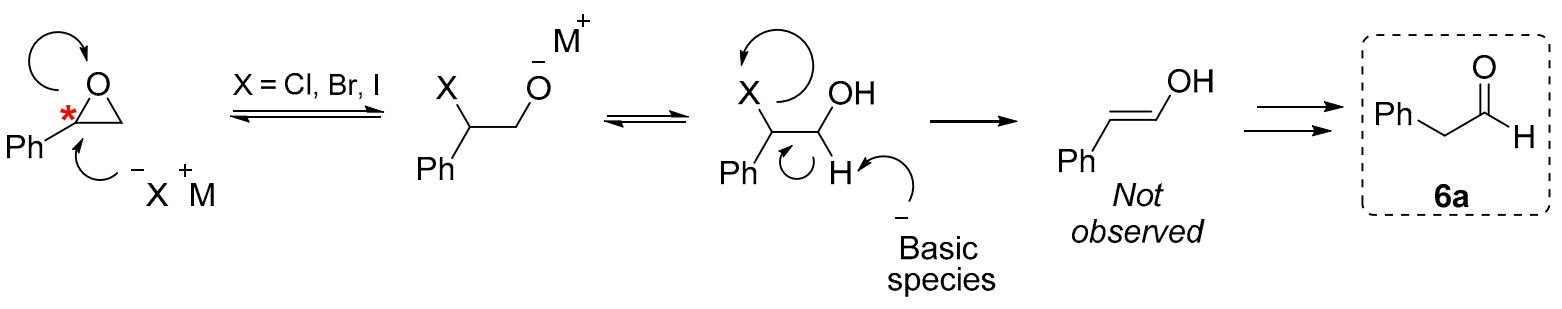

Scheme 2. Formation of phenylacetaldehyde by-product.

Particle size was found to have a dramatic effect. Particles sizes $<125 \mu \mathrm{m}$ and between $300-500 \mu \mathrm{m}$ achieved the best conversions, with the smallest particles being superior overall, and particle sizes between $125-300 \mu \mathrm{m}$ gave significantly worse conversions, on average $\sim 74-91 \%$ lower. The kelp synthesis was repeated in duplicate with the same trend being constantly observed achieving, $28.7 \%$ carbonate for $<125 \mathrm{~nm}$ particle size, $3.3 \%$ for $125-300 \mathrm{~nm}$ and $33.0 \%$ for $300-500 \mathrm{~nm}$. To explore this further, larger particle sizes $>500 \mu \mathrm{m}$ (which gave a good performance of $31.8 \%$ carbonate) were ground to $125-300 \mu \mathrm{m}$ and then used in the synthesis, yet these were found to still give lower conversions of 
only $5.3 \%$ styrene carbonate. Although the reason for this is not immediately apparent, this observation may be attributed to stirring kinetics: particles of certain size are able to agglomerate, therefore significantly reducing reaction rates. This effect considered, each particle size was investigated herein for each of the subsequent studies.

\subsection{Reproducibility Using Different Kelp Seaweeds}

Due to the variation in catalytic activity found between kelp and dulse, a more detailed study was performed focusing on whether a single species of seaweed could give reproducible catalytic activity if sourced from a different location. Three samples of kelp were sourced from the Plymouth Marine Laboratory and were harvested between September and November 2017 from Broadsands Beach, Paignton, UK. Kelp was chosen for investigation due to its superior activity.

\subsubsection{Catalytic Activity}

Each of the kelp samples (B to D) were dried and blended as previously described in Experimental Section 4.2. Identical reaction conditions and catalyst loading were used for the syntheses, with each of the different particle sizes investigated. Similar to previous observations, particle size had a significant effect, with seaweed particles sizes between 125-300 $\mu \mathrm{m}$ giving substantially lower conversions to styrene carbonate (for example, 75\% lower conversion between $<125 \mathrm{~nm}$ to $125-300 \mathrm{~nm}$ particle sizes for kelp D), Table 3. Despite extensive drying of the seaweed prior to use, diol by-product of between $22-38 \%$ was still observed.

Table 3. Conversion to styrene carbonate using different kelp seaweed samples.

\begin{tabular}{|c|c|c|c|c|c|c|c|c|}
\hline Kelp & $\begin{array}{l}\text { Particle } \\
\text { Size/ } \mu \mathrm{m}\end{array}$ & $\begin{array}{c}\text { Carbonate } \\
\text { 2a }(\%)\end{array}$ & $\begin{array}{c}\text { Diol 3a } \\
(\%)\end{array}$ & $\begin{array}{c}\text { BA 4a } \\
(\%)\end{array}$ & $\begin{array}{c}\text { CPE 5a } \\
(\%)\end{array}$ & $\begin{array}{c}\text { PAA 6a } \\
(\%)\end{array}$ & $\begin{array}{c}\text { Total } \\
\text { Conversion } \\
\text { from 1a }(\%)\end{array}$ & $\begin{array}{c}\text { Selectivity } \\
(\%)^{3}\end{array}$ \\
\hline \multirow{4}{*}{$\begin{array}{c}\text { Kelp B } \\
(18 / 09 / 17)^{1}\end{array}$} & $<125$ & 27.6 & 26.2 & 0.5 & 12.3 & 2.0 & 68.1 & 40.5 \\
\hline & $125-300$ & 8.4 & 24.0 & 0.5 & 11.3 & 1.7 & 45.4 & 18.5 \\
\hline & $300-500$ & 19.9 & 22.2 & 0.5 & 9.8 & 2.1 & 53.6 & 35.3 \\
\hline & $>500$ & 6.9 & 38.0 & 0.6 & 15.6 & 1.9 & 62.4 & 11.1 \\
\hline \multirow{4}{*}{$\begin{array}{c}\text { Kelp C } \\
(15 / 11 / 17)^{1}\end{array}$} & $<125$ & 26.4 & 27.4 & 0.5 & 12.2 & 1.7 & 67.6 & 39.0 \\
\hline & $125-300$ & 5.9 & 30.5 & 0.5 & 13.0 & 1.5 & 50.9 & 11.6 \\
\hline & $300-500$ & 21.7 & 23.8 & 0.5 & 10.9 & 1.8 & 58.2 & 37.2 \\
\hline & $>500$ & 25.6 & 32.7 & 0.4 & 13.2 & 3.1 & 74.7 & 34.4 \\
\hline \multirow{5}{*}{$\begin{array}{c}\text { Kelp D } \\
(20 / 11 / 17)^{1}\end{array}$} & 125 & 38.8 & 35.2 & 0.6 & 11.3 & 1.6 & 86.9 & 44.6 \\
\hline & $<123$ & $(63.7)^{2}$ & (28.2) & $(0.1)$ & (8.1) & $(0.07)$ & (100) & (63.7) \\
\hline & $125-300$ & 9.4 & 37.5 & 0.6 & 15.4 & 1.5 & 63.7 & 14.7 \\
\hline & $300-500$ & 30.2 & 27.7 & 0.6 & 11.4 & 1.5 & 70.8 & 42.6 \\
\hline & $>500$ & 37.3 & 36.2 & 0.3 & 12.6 & 2.5 & 88.6 & 42.1 \\
\hline
\end{tabular}

(1) Date that the seaweed was harvested. (2) Conversions when scale up to 20 mmols using a single Parr reactor. Full data showing conversion overtime given in SI, Figures S2 and S3) Selectivity towards carbonate 2a relative to total conversion from epoxide 1 a.

A number of drying techniques were employed, however TGIR analysis showed $\sim 8 \%$ water by mass was retained in the seaweeds after treatment (SI, Figures S3 and S4). Kelp D was found to give the highest conversions, achieving 38.8 and $37.3 \%$ 2a using particles sizes $<125 \mu \mathrm{m}$ and $>500 \mu \mathrm{m}$ respectively. Conversion to diol by-product 3a from residual water was also high $(79.2 \%$ for $<125 \mathrm{um}$ kelp D) when compared to kelp B (60.4\%) and C (60.9\%; SI, Table S3). Interestingly, quantities of 2-chloro-1-phenylethanol (5a) remained relatively consistent across the series, on average $12.4 \%$ and similarly, minor by-products $4 \mathbf{a}$ and 6 a also remained consistent giving an average of 0.5 and $1.9 \%$ respectively. Conversions to $\mathbf{2 a}$ between kelp B and $\mathrm{C}$ were comparable except for the particle size $>500 \mu \mathrm{m}$ for Kelp B, achieving very low conversions of only $6.9 \% \mathbf{2 a}$. The ratio of carbonate $\mathbf{2 a}$ to diol by-product 3a was relatively consistent for all particle sizes except reactions using kelp 125-300 $\mu \mathrm{m}$. This suggests formation of diol is independent to the formation of carbonate, where ring opening of the epoxide by water does not require any of (or access to) the catalytic species present in the seaweed. 
Kelp C showed very similar activity between the particles sizes of $<125 \mu \mathrm{m}$ and $>500 \mu \mathrm{m}$ of 26.4 and $25.6 \%$ conversion to $\mathbf{2 a}$. Despite the relatively good conversions, there was still variation in conversion to $\mathbf{2 a}$ amongst comparable samples in the order of $<125 \mu \mathrm{m}$ kelp D (38.8\%) superior to both $<125 \mu \mathrm{m}$ kelp B (27.6\%) and $<125 \mu \mathrm{m}$ kelp C (26.4\%). In order to further understand the distinct variation in activity, ICP-MS analysis of metal content along with an amino acid profile was constructed for Kelp samples B-D.

\subsubsection{Metal Concentrations}

ICP-MS analysis was performed externally and samples prepared as detailed in Experimental Section 4.10. Low concentrations of $\mathrm{Li}, \mathrm{Al}, \mathrm{Fe}, \mathrm{Cu}, \mathrm{Zn}, \mathrm{Sr}$ and $\mathrm{Ba}$ were found in all of the kelp samples, Table 4. Each of the seaweed samples contained a high proportion of sodium, with kelp D containing the most at $4.86 \%$ wt., kelp C $4.39 \%$ wt. and kelp B 4.13\% wt.; the opposite is true for calcium (D-1.33, C-1.45 and B-1.72\% wt.).

Table 4. Metal concentrations in kelp seaweed samples B-D.

\begin{tabular}{|c|c|c|c|c|c|c|c|c|c|c|c|c|c|}
\hline \multirow{2}{*}{ Kelp } & \multirow{2}{*}{$\begin{array}{l}\text { Harvest } \\
\text { Date }\end{array}$} & \multicolumn{11}{|c|}{ Metal Concentrations $\left(\mathrm{mg} \mathrm{g}^{-1}\right)$} & \multirow{2}{*}{$\begin{array}{c}<125 \mu \mathrm{m} \\
\text { Conversion to } \\
2 \mathrm{a}(\%)\end{array}$} \\
\hline & & $\mathrm{Li}$ & $\mathrm{Na}$ & $\mathrm{Mg}$ & $\mathrm{Al}$ & $\mathrm{K}$ & $\mathrm{Ca}$ & $\mathrm{Fe}$ & $\mathrm{Cu}$ & $\mathrm{Zn}$ & $\mathrm{Sr}$ & Ba & \\
\hline B & $18 / 09 / 17$ & 0.02 & 41.3 & 8.5 & 0.22 & 15.4 & 17.2 & 0.11 & 0.13 & 0.67 & 1.36 & 0.06 & 27.6 \\
\hline $\mathrm{C}$ & $15 / 11 / 17$ & 0.02 & 43.9 & 10.4 & 0.27 & 14.5 & 14.5 & 0.10 & 0.09 & 0.33 & 1.17 & 0.09 & 26.4 \\
\hline D & $20 / 11 / 17$ & 0.02 & 48.6 & 10.3 & 0.36 & 25.4 & 13.3 & 0.21 & 0.12 & 0.26 & 1.13 & 0.07 & 38.8 \\
\hline
\end{tabular}

Kelp D showed the highest $\mathrm{K}$ content of $2.54 \%$ wt., with both kelp B and C having lower concentration of $1.54 \%$ and $1.45 \%$ wt. respectively. This correlates well with previous observations, in particular, the high activity of $\mathrm{K}$ demonstrated in the model screen (Table 1 ) and the increased activity of kelp D shown in Table 3. The distribution of mineral content across the series does not appear to be affected by harvest date, where kelps $C$ and D were both sourced in November, yet have very different metal contents, whilst kelp B was harvested in September and has similar metal concentrations to kelp C. Whilst $\mathrm{K}$ content correlated well with activity, the amino acid profile and protein content of the kelp sample was also investigated.

\subsubsection{Amino Acid Profile and Protein Content}

CHN analysis of kelp samples B-D showed the total protein content [42] to be $7.8 \%$ for kelp B, 7.8\% for kelp $C$ and $8.8 \%$ for kelp D by mass. The amino acid profile was performed using an established technique [43] detailed in Experimental Section 4.6. Asparagine, glutamine, tryptophan and cysteine are absent from the data as a result of the hydrolysis preparation for HPLC analysis, Scheme 2; though it should be noted that, aspartic acid and glutamic acid are proportional to asparagine and glutamine originally present in the kelp samples prior to hydrolysis and the amine precursor will be referred to throughout the discussion. Interestingly, the proportion of basic (containing a second amine group) amino acids is relatively high for each kelp sample (Figure 1). Proline, aspartic acid, glutamic acid, arginine and lysine made up between $45-51 \%$ of the total amino acid content (TAAC) of the seaweed proteins present in the kelp. Interestingly, only low quantities of histidine were found in kelp samples B and C, whilst being absent in kelp D. Proline, asparagine and glutamine were found to be the dominant amino acids for all kelp samples with kelp D containing the most of these amino acids, correlating well with catalyst activity. 




Figure 1. \% weight amino acids relative to total protein content for kelp B, C and D. Asterisks against asparagine $^{*}$ and glutamine* denote conversion to aspartic and glutamic acid. Tryptophan ${ }^{* *}$ and cysteine $^{* *}$ highlight an expected absence of these amino acids, as a result of the work up procedure and analytical method.

Although it is unlikely that neutral amino acids proline and alanine would contribute significantly towards the catalytic activity found within the system, any of the basic amino acids (including carboxamides asparagine, glutamine as well as lysine) are likely to contribute towards the activation of $\mathrm{CO}_{2}$ (Figure 1). However, activity has been shown to be dependent on amino acid type (Table 1), where despite the relatively high ratio of lysine present in kelp $C$, this particular amino acid does not have high activity when used alone suggesting that the lower conversions seen with kelp $C$ are more related to the concentration of other amino acids as well as metal halides. Nevertheless, mechanistic pathways have been suggested in the literature [36], where the basic amines are able to form a carbamate salt 7 with $\mathrm{CO}_{2}$, which is then able to subsequently attack halide activated alkoxide intermediate 8 regenerating the metal halide catalyst, Scheme 3. Cyclisation of intermediate 9 forms the cyclic carbonate product and the free amine co-catalyst.


Scheme 3. Catalytic cycle of a basic amino acid with metal halide. 


\subsection{Reuse of Kelp Seaweeds}

Due to the proposed partially heterogeneous catalytic nature of this system, reuse of the kelp catalysts was investigated, Table 5. After first use for the synthesis of $2 a$, each of the kelp catalysts was filtered from the reaction mixture, washed three times with deuterated chloroform for ${ }^{1} \mathrm{H}-\mathrm{NMR}$ analysis and dried in a vacuum oven overnight as detailed in Experimental Section 4.7. Prior to reuse in a second synthesis, the kelp catalysts were analyzed using TGA which showed that after one use, an average mass loss of $9.5 \%$ organics relative to residual inorganic material occurred. Reaction conditions used for the second use were identical to the first use syntheses, with the quantity of epoxide being adjusted to maintain an $80 \% \mathrm{wt}$. catalyst to epoxide ratio and account for loss of material during the isolation, analysis and washing stage. In all cases the second use conversions were significantly lower than conversions obtained during the first use, where kelp B and C conversions reduced by $76.8 \%$ and $71.6 \%$ with kelp D reducing by $58.0 \%$. The higher reuse conversions obtained with latter may be attributed to kelp D having increased concentrations of $\mathrm{K}$ and TAAC relative to kelp $\mathrm{B}$ and $C$ prior to use. Similarly, conversion to by-product 5 a also reduced by around $44-60 \%$ across the series, suggesting a loss of chloride ions from the system. An increase in ratio of 2a:3a suggests further incorporation of water into the Kelp during the isolation and reuse process.

Table 5. Effect of reuse on kelp activity in the synthesis of styrene carbonate.

\begin{tabular}{cccccccccc}
\hline Kelp & Use & $\begin{array}{c}\text { Carbonate 2a } \\
\mathbf{( \% )}\end{array}$ & $\begin{array}{c}\text { Reduction in } \\
\text { Activity (\%) }\end{array}$ & $\begin{array}{c}\text { Diol 3a } \\
\mathbf{( \% )}\end{array}$ & $\begin{array}{c}\text { Ratio } \\
\mathbf{2 a : 3 a}\end{array}$ & $\begin{array}{c}\text { BA 4a } \\
\mathbf{( \% )}\end{array}$ & $\begin{array}{c}\text { CPE 5a } \\
\mathbf{( \% )}\end{array}$ & $\begin{array}{c}\text { PAA 6a } \\
\mathbf{( \% )}\end{array}$ & $\begin{array}{c}\text { Selectivity } \\
\mathbf{( \% )}\end{array}$ \\
\hline \multirow{2}{*}{ B } & 1st & 27.6 & - & 26.2 & $1: 0.95$ & 0.5 & 12.3 & 2.0 & 40.5 \\
& 2nd & 6.4 & 76.8 & 21.9 & $1: 3.47$ & 0.4 & 5.5 & 0.9 & 18.4 \\
\hline \multirow{2}{*}{ C } & 1st & 26.4 & - & 27.4 & $1: 1.04$ & 0.5 & 12.2 & 1.7 & 39.0 \\
& 2nd & 7.5 & 71.6 & 23.7 & $1: 3.15$ & 0.4 & 6.6 & 1.0 & 19.4 \\
\hline \multirow{2}{*}{$\mathbf{D}$} & 1st & 38.8 & - & 35.2 & $1: 0.91$ & 0.6 & 11.3 & 1.6 & 44.6 \\
& 2nd & 16.3 & 58.0 & 20.3 & $1: 1.25$ & 0.8 & 6.5 & 1.2 & 44.2 \\
\hline
\end{tabular}

(1) Expressed as a percentage relative to the conversions achieved during the first use of the kelp catalysts.

As none of the potential catalytically active species within the seaweed are covalently bound, it is likely that proteins, amino acids and metals are dissolved out of the seaweed polysaccharide structure by the epoxide, product or by-products throughout the reaction; $\mathrm{CO}_{2}$ gas expansion may aid this too. Furthermore, at reaction temperatures of $120^{\circ} \mathrm{C}$ the seaweed proteins are likely to denature and depolymerize making the subsequent oligomeric species more soluble in the reaction mixture. Methods to circumvent the issue of leaching are not immediately obvious due to the nature of the raw seaweed material being used, however, subsequent isolation and reuse of the active species may be possible with further investigation.

\subsection{Substrate Scope Using Kelp D as a Catalyst}

The substrate scope of kelp D was investigated due to its superior activity over kelp B and C, Table 6. Reaction conditions used were identical to the previously performed experiments, as detailed in Experimental Section 4.5. Interestingly, 1,2-epoxydecane (1e) gave very poor conversions to $2 \mathbf{e}$ with no conversion at all to by-products $4-5 \mathbf{e}$. This may be attributed to the low polarity of the substrate, where minimal quantities of the highly polar active species, such as metal halides, are able to dissolve into the reaction medium and instead are retained within the seaweed structure. Conversely, production of diol by-product appeared to be much more of a problem when using polar epoxides $\mathbf{1 b}$,c. Despite the relatively high quantities of $\mathbf{3 c}$ by-product, conversions to $\mathbf{2 c}$ were good achieving $42.2 \%$. Similarly, conversions to $\mathbf{2} \mathbf{b}$ were good (43.8\%) despite the relatively high formation of $\mathbf{5 b}$ of $27.4 \%$. This may be attributed to the increased activity of the epoxide towards the $\mathrm{OH}$ or $\mathrm{Cl}$, increasing delta positive character on secondary carbon of the epoxide and allowing increased rates of nucleophilic attack from either a halide or water. 4-Chlorostyrene oxide (1d) gave much lower conversions compared with 1a most likely due to the deactivating effect of the $\mathrm{p}-\mathrm{Cl}$. 
Table 6. Substrate scope using kelp D as a catalyst.

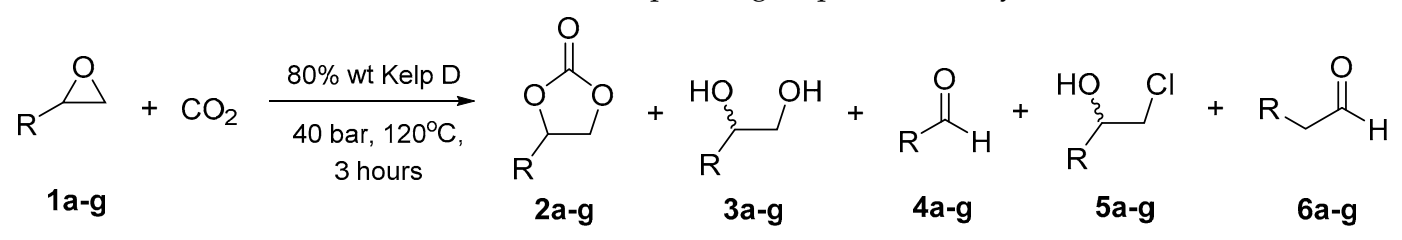

a) $\mathrm{R}=\mathrm{Ph}$, b) $\mathrm{R}=\mathrm{CH}_{2} \mathrm{OH}$, c) $\mathrm{R}=\mathrm{CH}_{2} \mathrm{Cl}$, d) $\mathrm{R}=\mathrm{Ph}(\mathrm{Cl})$, e) $\mathrm{R}=\left(\mathrm{CH}_{2}\right)_{7} \mathrm{CH}_{3}$,

\begin{tabular}{|c|c|c|c|c|c|c|c|c|}
\hline Epoxide & $2 a-g(\%)$ & $3 a-g(\%)$ & $\begin{array}{c}\text { Ratio } \\
\text { 2a-g:3a-g }\end{array}$ & $4 a-g(\%)$ & $5 a-g(\%)$ & $6 a-g(\%)$ & $\begin{array}{c}\text { Total } \\
\text { Conversion } \\
\text { from 1a }(\%)\end{array}$ & $\begin{array}{c}\text { Selectivity } \\
\text { (\%) }\end{array}$ \\
\hline $1 \mathrm{a}$ & 38.8 & 35.2 & 1:0.91 & 0.6 & 11.3 & 1.6 & 86.9 & 44.6 \\
\hline $1 b$ & 43.8 & 28.7 & 1:0.66 & 0.03 & 27.4 & 0 & 100 & 43.8 \\
\hline $1 c$ & 42.2 & 44.7 & 1:1.06 & 0.0 & 13.0 & 0 & 100 & 42.2 \\
\hline $1 d^{1}$ & 20.6 & 20.8 & 1:1.01 & 0.4 & 0.6 & 0.4 & 54.6 & 37.7 \\
\hline $1 \mathrm{e}$ & 0.5 & 8.6 & $1: 18.5$ & 0.0 & 0.0 & 0.1 & 9.1 & 5.1 \\
\hline
\end{tabular}

(1) 4-Chlorostyrene oxide.

\section{Conclusions}

The initial model study supported previous observations that amino acids are able to offer impressive synergistic effects when used with a range of metals halides. However, in contrast to this KI was found to be superior to all model catalytic systems investigated when used without an amino acid co-catalyst. This study has shown that raw and (relatively) unprocessed seaweed can be used for the synthesis of cyclic carbonates and $\mathrm{CO}_{2}$. Of the two species investigated, kelp was found to contain a higher proportion of catalytically active species. Although there was distinct variation in the activity of the seaweed catalysts, this difference could not be correlated with either the location or date of harvesting. Despite both kelp C and D being harvested in November at the same location, the latter was found to be $\sim 47 \%$ more active, attributed to the increased quantities of $\mathrm{K}$ and basic amino acids found within the seaweed structure. All seaweed samples suffered from the formation of diol by-product due to residual water being retained in the seaweed despite extensive drying. Moreover, a chloro functionalized by-product 5 a was also detected by GC/MS and ${ }^{1} \mathrm{H}-\mathrm{NMR}$, typically accounting for $12 \%$ of total conversion along with small quantities of benzaldehyde (4a) and phenylacetaldehyde (6a) Each of these by-products has useful applications, particularly in the production of pharmaceuticals, fragrances and plastics. Further work should investigate the possibility of calcination of the seaweeds to remove all traces of water, yet avoid significant decomposition of the amino acid species. It should be noted that although the relative quantities of amino acids was determined via hydrolysis and HPLC analysis, the form of the amino acids during the reaction was not known (extent of protein denaturing, depolymerization etc).

Interestingly, particle size was found to have a significant effect on conversions with particle sizes between $125-300 \mu \mathrm{m}$ giving consistently low conversions throughout the study for all seaweed samples. This was attributed to the stirring kinetics, where particle sizes between 125-300 $\mu \mathrm{m}$ are more able to agglomerate and restrict diffusion of reactant species. Use of a solvent, such as propylene carbonate, to allow high concentrations of catalyst to be used, yet maintain efficient stirring would help identify if agglomeration is the core problem.

Further investigation into the use of other seaweed types (non-edible as well as edible) sourced from locations across the globe would highlight the full potential seaweed has to offer as an entirely natural, benign and cheap catalyst for the synthesis of cyclic carbonates. 


\section{Experimental Section}

\subsection{Chemicals and Equipment}

$\mathrm{KI}, \mathrm{KBr}, \mathrm{NaI}, \mathrm{CDCl}_{3}$, histidine, glycine, lysine, glycidol and 2-(4-chlorophenyl)oxirane were purchased from Sigma Aldrich Company Ltd. (Dorset, UK). NaCl, 1,2-epoxydecane, and epichlorohydrin were purchased from Fischer Scientific (Leicestershire, UK). $\mathrm{NaBr}$ and styrene oxide were purchased from ACROS Chemicals (part of Thermo Fisher Scientific, Leicestershire, UK). Kelp and dulse listed in Table 1 were purchased from Irishseaweeds.com and was sourced from the Northern Irish north coast. kelp samples B, C and D were kindly supplied from Plymouth Marine Laboratory (Plymouth, UK), harvested from Broadlands Beach and Elberry Cove in Paignton.

Nuclear magnetic resonance spectroscopy was carried out using a JEOL $400 \mathrm{MHz}$ instrument (JEOL, Tokyo, Japan) in deuterated chloroform. TG-IR was carried out using a STA409 system (Netsch, Selb, Germany) linked to a gas cell in an Equinox 55 Infra-red spectrometer (Bruker, Billerica, MA, USA) by a heated gas line. Amino acid content was determined using an Infinity 1200 HPLC system (Agilent, Santa Clara, CA, USA). ICP-MS analysis was performed at the University of Edinburgh on an Elan 6100 DRC instrument (Perkin-Elmer, Waltham, MA, USA) and an Element 2 system (Thermo-Finnegan, Waltham, MA, USA). GC/MS data was obtained on a JEOL JMS-T200GC AccuTOF (JEOL) and Agilent 7890B GC (Agilent). ESI was performed on a Bruker compact time of flight mass spectrometer (Bruker).

\subsection{Seaweed Preparation before Analysis and use as a Catalyst}

The pre-dried raw seaweed was cut into $\sim 2 \mathrm{~cm}^{2}$ squares and then blended. The blended seaweed was sieved in order to separate particles by their sizes: $<125 \mu \mathrm{m}, 125-300 \mu \mathrm{m}, 300-500 \mu \mathrm{m}$, and $>500 \mu \mathrm{m}$. These samples were then dried in a vacuum oven at $\sim 60^{\circ} \mathrm{C}$ for $24 \mathrm{~h}$ and then freeze dried before storage in a desiccator.

\subsection{Standard Synthesis of Styrene Carbonate Using Metal Halides and/or Amino Acids}

Styrene oxide $(0.57 \mathrm{~mL}, 5 \mathrm{mmol})$ was added to a vessel within the multipoint reactor. Either a metal halide, an amino acid, or a combination of the two was added to the vessel with each component being added at $2 \mathrm{~mol} \%$ with respect to styrene oxide. The vessel was then pressurized to $40 \mathrm{bar}$ of $\mathrm{CO}_{2}$ for $3 \mathrm{~h}$ at $120^{\circ} \mathrm{C}$ with stirring. The reactor was then submerged in liquid nitrogen until the temperature within the reactor had reached $\sim 10{ }^{\circ} \mathrm{C}$, at which point the pressure within the reactor was released. The reaction mixtures were then extracted and analyzed by ${ }^{1} \mathrm{H}-\mathrm{NMR}$ spectroscopy to calculate the conversions.

\subsection{Standard Synthesis of Styrene Carbonate Using Seaweeds Kelp or Dulse}

Styrene oxide $(0.57 \mathrm{~mL}, 5 \mathrm{mmol})$ was added to a vessel within the multipoint reactor. $80 \% \mathrm{wt}$. relative to epoxide of either kelp or dulse was added to the reactor having been prepared as stated in Experimental Section 4.2. The vessel was then pressurized to 40 bar of $\mathrm{CO}_{2}$ for $3 \mathrm{~h}$ at $120^{\circ} \mathrm{C}$ with stirring. The reactor was then submerged in liquid nitrogen until the temperature within the reactor had reached $\sim 10^{\circ} \mathrm{C}$, at which point the pressure within the reactor was released. The reaction mixtures were then extracted and analyzed by ${ }^{1} \mathrm{H}-\mathrm{NMR}$ spectroscopy to calculate the conversions.

\subsection{Synthesis of Different Carbonates Using Kelp D}

Five mmol of four different epoxides was added to separate vessels within a multipoint pressure reactor. Kelp sample B, particle size $<125 \mu \mathrm{m}$ was added to the vessel at a loading of $50 \%$ weight with respect to the mass of epoxide. The vessel was then pressurized to $40 \mathrm{bar}$ of $\mathrm{CO}_{2}$ for $3 \mathrm{~h}$ at $120{ }^{\circ} \mathrm{C}$ with stirring. The reactor was then submerged in liquid nitrogen until the temperature within the reactor had reached $\sim 10^{\circ} \mathrm{C}$, at which point the pressure within the reactor was released. The reaction mixture was then extracted by dissolving in deuterated chloroform followed by filter paper separation of the 
seaweed and the reaction solution. The remaining oil was then analyzed ${ }^{1} \mathrm{H}-\mathrm{NMR}$ spectroscopy to calculate conversions.

\subsection{Amino Acid Profile}

Hydrolysis of the kelp samples was done as follow: $10 \mathrm{mg}$ of algae were suspended in $25 \mathrm{~mL}$ of $6 \mathrm{M} \mathrm{HCl}$ with $1 \% w / v$ phenol and heated at $150^{\circ} \mathrm{C}$ for $30 \mathrm{~min}$ in a CEM Discover microwave (CEM, Buckingham, UK). The resulting mixture was filtered and evaporated under reduce pressure. The resulting solid was re-suspended in $30 \mathrm{~mL}$ of suspension solution consisting of Eluent A:MeOH:ISTDsol (5:4:1). The suspension was sonicated for $10 \mathrm{~s}$ and filtrated through $0.22 \mu \mathrm{m}$ Whatman filters. An Agilent Infinity 1200 HPLC system equipped with a Poroshell 120 EC-C18 $4.6 \times 100 \mathrm{~mm}, 2.7 \mu \mathrm{m}$ diameter column was used to perform the chromatographic separation. Temperature of the oven was set at $45^{\circ} \mathrm{C}$, a quaternary pump (G7111B) was used to pump eluents through the column with a pressure limit of 600 bar and a flow set at $0.4 \mathrm{~mL} / \mathrm{min}$. A DAD detector (G7115A) was set at wavelength $263 \mathrm{~nm}$ (FMOC) and $338 \mathrm{~nm}$ (OPA). Settings of the sampler (G7129A) were the following: draw speed- $200 \mu \mathrm{L} / \mathrm{min}$, eject speed- $400 \mu \mathrm{L} / \mathrm{min}$.

\subsection{Reusability Study}

Kelp sample B, C or D, of particle size $<125 \mu \mathrm{m}$ was added to a vessel in a multipoint pressure reactor. These Kelp samples had already been used as a catalyst once before and had been washed in chloroform and subsequently dried in air prior to reuse. Styrene oxide was added at such a quantity that Kelp loading was $80 \%$ weight of styrene oxide. The vessel was then pressurized to 40 bar of $\mathrm{CO}_{2}$ for $3 \mathrm{~h}$ at $120^{\circ} \mathrm{C}$ with stirring. The reactor was then submerged in liquid nitrogen until the temperature within the reactor had reached $\sim 10{ }^{\circ} \mathrm{C}$, at which point the pressure within the reactor was released. The reaction mixture was then extracted by dissolving in deuterated chloroform followed by filter paper separation of the seaweed and the reaction solution, followed by ${ }^{1} \mathrm{H}-\mathrm{NMR}$ analysis.

\subsection{Pressure Study}

Method as with 4.3, except with different $\mathrm{CO}_{2}$ pressure of 10, 20, 30 and 40 bar.

\subsection{Thermal Gravimetric Infrared Spectrometry (TGIR)}

Approximately $50 \mathrm{mg}$ of kelp sample was used and placed under nitrogen with a flow rate of $100 \mathrm{~cm}^{3} \mathrm{~min}^{-1}$. The sample was then placed under vacuum after being backfilled with nitrogen twice and heated to $500 \mathrm{~K}$ at a ramp rate of $2.5 \mathrm{~K} \mathrm{~min}^{-1}$.

\subsection{ICP-MS}

ICP-MS was run as a service by Dr Lorna Eades, ICP Facility Manager, University of Edinburgh (Edinburgh, Scotland). $400 \mathrm{mg}$ of kelp sample B-D was taken and calcined at $450{ }^{\circ} \mathrm{C}$ for $2 \mathrm{~h}$ and then left in a desiccator to cool. $10 \mathrm{mg}$ of the residual sample was digested in $2 \mathrm{~mL}$ ultrapure $70 \%$ nitric acid $(\geq 99.999 \%)$ and diluted to a total volume of $100 \mathrm{~mL}$ using ultrapure water. $10 \mathrm{~mL}$ of each sample solution was sent for ICP-MS analysis.

\subsection{1. ${ }^{1} \mathrm{H}-\mathrm{NMR}$ Conversion Calculation}

Conversions were calculated using integrals obtained from ${ }^{1} \mathrm{H}-\mathrm{NMR}$ spectra. An example ${ }^{1} \mathrm{H}-\mathrm{NMR}$ spectrum of the conversion to styrene carbonate using kelp B 300-500 nm particle size, as shown in Table 3, can be seen in Supplementary Information Figure S5. A typical calculation is also shown, where the conversion of any particular species is found by dividing the integral with the sum of the integrals for all species.

Supplementary Materials: The following are available online, Table S1a: Conversions to styrene carbonate and diol by-product using metal halides and histidine co-catalyst, Table S1b: Conversion to styrene carbonate and diol 
by-product using metal halides lysine co-catalyst, Table S1c: Conversion to styrene carbonate and diol by-product using metal halides glycine co-catalyst, Table S1d: Conversion to styrene carbonate and diol by-product using metal halides alone, Table S1e: Conversion to styrene carbonate and diol by-product using amino acids alone, Figure S1: Variation in kelp catalyst loading in the synthesis of styrene carbonate, Table S2: Effect of $\mathrm{CO}_{2}$ pressure on conversion to styrene carbonate using kelp $\mathrm{D}<125 \mathrm{~nm}$ as a catalyst, Figure S2: Conversion to styrene carbonate over time using kelp D catalyst and larger reaction scale of 20 mmols in a single Parr reactor, Table S3: Calculation of water content from TGIR analysis of unused kelp seaweeds B-D < 125, Table S4: \% Organic vs inorganic content for kelp seaweeds B, C and D, Figure S3: TGIR Analysis of kelp B (Red), C (Blue) and D (Green). TG used to assess residual moisture content of the dried seaweeds, Figure S4: IR over time to measure water loss. TGIR of kelp B (left), kelp C (middle) and kelp D (right), Figure S5: ${ }^{1} \mathrm{H}$ NMR of conversion to styrene carbonate using Kelp B 300-500 nm particle size as shown in table 3 along with an example carbonate conversion calculation, Figure S6: High resolution $\mathrm{M} / \mathrm{S}$ of reaction mixture-conversion to styrene carbonate using kelp $\mathrm{D}<125 \mathrm{~nm}$ particle size as shown in table 3, Figure S7: M/S of Peak 1-Benzaldehyde, Figure S8: M/S of Peak 2-Styrene Oxide, Figure S9: M/S of Peak 3-1-Phenyl-2-chloroethanol, Figure S10: M/S of Peak 4-1-Phenyl-1,2-ethanediol, Figure S11: M/S of Peak 5-Styrene carbonate, Figure S12: High resolution M/S of reaction mixture showing phenylacetaldehyde, 1-phenyl-1,2-ethanediol and styrene carbonate, Figure 13: ICP-MS raw data, Method S1: Detailed HPLC method for amino acid analysis.

Author Contributions: Conceptualization, J.W.C.; data curation, T.G., A.P. and J.W.C.; formal analysis, T.G., Y.L. and J.W.C.; methodology, J.W.C. and D.J.M.; validation, T.G., J.W.C., D.J.M., M.N.; investigation, T.G., Y.L. and J.W.C.; resources, D.J.M. and M.N.; writing-original draft preparation, J.W.C.; writing-review and editing, J.W.C., Y.L., D.J.M. and A.P.; visualization, J.W.C.; supervision, J.W.C. and D.J.M.

Funding: Alessandro Pellis thanks the FWF Erwin Schrödinger fellowship (grant agreement J 4014-N34) for financial support.

Acknowledgments: We would like to thank Alice Fan for guiding us in sourcing the seaweeds and Mike Allen of Plymouth Marine Laboratory Ltd for suppling us with the Kelp seaweeds B, C and D.

Conflicts of Interest: The authors declare no conflict of interest.

\section{References}

1. Smith, M.R.; Myers, S.S. Impact of anthropogenic $\mathrm{CO}_{2}$ emissions on global human nutrition. Nat. Clim. Chang. 2018, 8, 834. [CrossRef]

2. Dong, K.; Jiang, H.; Sun, R.; Dong, X. Driving forces and mitigation potential of global $\mathrm{CO}_{2}$ emissions from 1980 through 2030: Evidence from countries with different income levels. Sci. Total Environ. 2019, 649, 335-343. [CrossRef] [PubMed]

3. Foster, G.L.; Rohling, E.J. Relationship between sea level and climate forcing by $\mathrm{CO}_{2}$ on geological timescales. Proc. Natl. Acad. Sci. USA 2013, 110, 1209-1214. [CrossRef] [PubMed]

4. Munday, P.L.; McCormick, M.I.; Nilsson, G.E. Impact of global warming and rising $\mathrm{CO}_{2}$ levels on coral reef fishes: What hope for the future? J. Exp. Biol. 2012, 215, 3865-3873. [CrossRef] [PubMed]

5. Cherchi, A.; Masina, S.; Navarra, A. Impact of extreme $\mathrm{CO}_{2}$ levels on tropical climate: A CGCM study. Clim. Dyn. 2008, 31, 743-758. [CrossRef]

6. Le Quéré, C.; Andres, R.J.; Boden, T.; Conway, T.; Houghton, R.A.; House, J.I.; Marland, G.; Peters, G.P.; van der Werf, G.; Ahlström, A.; et al. The global carbon budget 1959-2011. Earth Syst. Sci. Data 2013, 5, $165-185$. [CrossRef]

7. Harwatt, H.; Sabat, J.; Eshel, G.; Soret, S.; Ripple, W. Substituting beans for beef as a contribution toward US climate change targets. Clim. Chang. 2017, 143, 261-270. [CrossRef]

8. Lerner, H.; Algers, B.; Gunnarsson, S.; Nordgren, A. Stakeholders on Meat Production, Meat Consumption and Mitigation of Climate Change: Sweden as a Case. J. Agric. Environ. Ethics 2013, 26, 663-678. [CrossRef]

9. Nordgren, A. Ethical Issues in Mitigation of Climate Change: The Option of Reduced Meat Production and Consumption. J. Agric. Environ. Ethics 2012, 25, 563-584. [CrossRef]

10. Iwasa, S.; Nishi, T.; Nakamura, S. Enhancement of rapid charging capability of organic radical battery using ethylene carbonate-based electrolyte containing LiFSI. J. Power Sources 2018, 402, 157-162. [CrossRef]

11. Clark, J.H.; Farmer, T.J.; Ingram, I.D.V.; Lie, Y.; North, M. Renewable Self-Blowing Non-Isocyanate Polyurethane Foams from Lysine and Sorbitol. Eur. J. Org. Chem. 2018, 31, 4265-4271. [CrossRef]

12. Tominaga, Y. Ion-conductive polymer electrolytes based on poly(ethylene carbonate) and its derivatives. Polym. J. 2017, 49, 291-299. [CrossRef] 
13. Guerin, W.; Diallo, A.K.; Kirilov, E.; Helou, M.; Slawinski, M.; Brusson, J.M.; Carpentier, J.F.; Guillaume, S.M. Enantiopure Isotactic PCHC Synthesized by Ring-Opening Polymerization of Cyclohexene Carbonate. Macromolecules 2014, 47, 4230-4235. [CrossRef]

14. Jun, J.O.; Lee, J.; Kang, K.H.; Song, I.K. Synthesis of Dimethyl Carbonate from Ethylene Carbonate and Methanol Over Nano-Catalysts Supported on $\mathrm{CeO}_{2}-\mathrm{MgO}$. J. Nanosci. Nanotechnol. 2015, 15, 8330-8335. [CrossRef] [PubMed]

15. Wang, P.; Liu, S.; Zhoua, F.; Yanga, B.; Alshammari, A.S.; Lu, L.; Deng, Y. Two-step synthesis of dimethyl carbonate from urea, ethylene glycol and methanol using acid-base bifunctional zinc-yttrium oxides. Fuel Process. Technol. 2014, 126, 359-365. [CrossRef]

16. Parker, H.L.; Sherwood, J.; Hunt, A.J.; Clark, J.H. Cyclic Carbonates as Green Alternative Solvents for the Heck Reaction. ACS Sustain. Chem. Eng. 2014, 2, 1739-1742. [CrossRef]

17. Castro-Osma, J.A.; Comerford, J.W.; Heath, S.; Jones, O.; Morcillo, M.; North, M. Quinine catalysed asymmetric Michael additions in a sustainable solvent. RSC Adv. 2015, 5, 3678-3685. [CrossRef]

18. Wu, X.; North, M. A Bimetallic Aluminium(Salphen) Complex for the Synthesis of Cyclic Carbonates from Epoxides and Carbon Dioxide. ChemSusChem 2017, 10, 74-78. [CrossRef]

19. Whiteoak, C.J.; Kielland, N.; Laserna, V.; Escudero-Adan, E.C.; Martin, E.; Kleij, A.W. A Powerful Aluminum Catalyst for the Synthesis of Highly Functional Organic Carbonates. JACS 2013, 135, 1228-1231. [CrossRef]

20. Liang, S.; Liu, H.; Jiang, T.; Song, J.; Yang, G.; Han, B. Highly efficient synthesis of cyclic carbonates from $\mathrm{CO}_{2}$ and epoxides over cellulose/KI. Chem. Commun. 2011, 47, 2131-2133. [CrossRef]

21. Song, J.; Zhang, Z.; Han, B.; Hu, S.; Li, W.; Xie, Y. Synthesis of cyclic carbonates from epoxides and $\mathrm{CO}_{2}$ catalyzed by potassium halide in the presence of $\beta$-cyclodextrin. Green Chem. 2008, 10, 1337. [CrossRef]

22. Song, J.; Zhang, B.; Zhang, P.; Ma, J.; Liu, J.; Fan, H.; Jiang, T.; Han, B. Highly efficient synthesis of cyclic carbonates from $\mathrm{CO}_{2}$ and epoxides catalyzed by KI/lecithin. Catal. Today 2012, 183, 130-135. [CrossRef]

23. Zhou, Y.; Hu, S.; Ma, X.; Liang, S.; Jiang, T.; Han, B. Synthesis of cyclic carbonates from carbon dioxide and epoxides over betaine-based catalysts. J. Mol. Catal. Chem. 2008, 284, 52-57. [CrossRef]

24. Qi, C.; Jiang, H. Histidine-catalyzed synthesis of cyclic carbonates in supercritical carbon dioxide. Sci. China Chem. 2010, 53, 1566-1570. [CrossRef]

25. Fraas, F.; Partridge, E.P. Potash from Polyhalite by Reduction Process Extraction of Potassium and the Production of Potassium Carbonate. Ind. Eng. Chem. 1936, 28, 956-962. [CrossRef]

26. Aronov, A.G.; Mukhamediyev, S.A.; Aronova, T.I. Stress state of the earth's crust and seismicity in a potassium salt mining region of Belarus. Acta Geod. Geophys. 2014, 49, 125-134. [CrossRef]

27. Ladrera, R.; Canedo-Arguelles, M.; Prat, N. Impact of potash mining in streams: The Llobregat basin (northeast Spain) as a case study. J. Limnol. 2017, 76, 343-354. [CrossRef]

28. Jeswiet, J.; Archibald, J.; Thorley, U.; De Souza, E. Energy Use in Premanufacture (Mining). Procedia CIRP 2015, 29, 816-821. [CrossRef]

29. Key, T.J.A.; Thorogood, M.; Keenan, J.; Long, A. Raised thyroid stimulating hormone associated with kelp intake in British vegan men. J. Hum. Nutr. Diet. 1992, 5, 323-326. [CrossRef]

30. Mussig, K.; Thamer, C.; Bares, R.; Lipp, H.P.; Haring, H.U.; Gallwitz, B. Iodine-Induced Thyrotoxicosis After Ingestion of Kelp-Containing Tea. J. Gen. Intern. Med. 2006, 21, C11-C14. [CrossRef]

31. Rosen, J.E.; Gardiner, P.; Saper, R.B.; Pearce, E.N.; Hammer, K.; Gupta-Lawrence, R.L.; Lee, S.L. Kelp use in patients with thyroid cancer. Endocrine 2014, 46, 123-130. [CrossRef]

32. Peng, Y.; Hu, J.; Yang, B.; Lin, X.P.; Zhou, X.F.; Yang, X.W.; Liu, Y. Chapter 5-Chemical composition of seaweeds, Chapter 6-Seaweed proteins, peptides, and amino acids and Chapter 7-Seaweed Carbohydrates. In Seaweed Sustainability_Food and Non-Food Applications, 1st ed.; Tiwari, B.K., Troy, D.J., Eds.; Academic Press Elsevier: London, UK, 2015.

33. Blunden, G.; Challen, S.B.; Woods, D.L. Seaweed extracts as fertilisers. J. Sci. Food Agric. 1968, 19, $289-292$. [CrossRef] [PubMed]

34. Bixler, H.J.; Porse, H. A decade of change in the seaweed hydrocolloids industry. J. Appl. Phycol. 2011, 23, 321-335. [CrossRef]

35. Makkar, H.P.S.; Tran, G.; Heuzé, V.; Giger-Reverdin, S.; Lessire, M.; Lebas, F.; Ankers, P. Seaweeds for livestock diets: A review. Anim. Feed Sci. Technol. 2016, 212, 1-17. [CrossRef] 
36. Roshan, K.R.; Kathalikkattil, A.C.; Tharun, J.; Kim, D.W.; Won, Y.S.; Park, D.W. Amino acid/KI as multi-functional synergistic catalysts for cyclic carbonate synthesis from $\mathrm{CO}_{2}$ under mild reaction conditions: A DFT corroborated study. Dalton Trans. 2014, 43, 2023-2031. [CrossRef] [PubMed]

37. Roshan, K.; Kathalikkattil, A.; Tharun, J.; Kim, D.; Won, Y.; Qi, Y.; Cheng, W.; Xu, F.; Chen, S.; Zhang, S. Amino acids/superbases as eco-friendly catalyst system for the synthesis of cyclic carbonates under metal-free and halide-free conditions. Synth. Commun. 2018, 48, 876-886. [CrossRef]

38. Home-Irish Seaweeds. Available online: www.Irishseaweeds.com (accessed on 14 April 2016).

39. Beebe, T.R.; Hii, P.; Reinking, P. Oxidative cleavage of 1,2-diols with N-iodosuccinimide. J. Org. Chem. 1981, 46, 1927-1929. [CrossRef]

40. Mojtahedi, M.M.; Saidi, M.R.; Bolourtchian, M.; Shirzi, J.S. Microwave assisted selective oxidation of benzylic alcohols with calcium hypochlorite under solvent-free conditions. Monatsh. Chem. 2001, 132, 655-658. [CrossRef]

41. Ren, Q.G.; Chen, S.Y.; Zhou, X.T.; Ji, H.B. Highly efficient controllable oxidation of alcohols to aldehydes and acids with sodium periodate catalyzed by water-soluble metalloporphyrins as biomimetic catalyst. Bioorg. Med. Chem. 2010, 18, 8144-8149. [CrossRef]

42. Spaha, I.F.; Edsall, J.T. Amino Acid Composition of Human and Bovine Serum Mercaptalbumins. J. Biol. Chem. 1964, 239, 850-854.

43. Meussen, B.J.; van Zeeland, A.N.T.; Bruins, M.E.; Sanders, J.P.M. A Fast and Accurate UPLC Method for Analysis of Proteinogenic Amino Acids. Food Anal. Methods 2014, 7, 1047-1055. [CrossRef]

Sample Availability: Not available.

(C) 2019 by the authors. Licensee MDPI, Basel, Switzerland. This article is an open access article distributed under the terms and conditions of the Creative Commons Attribution (CC BY) license (http://creativecommons.org/licenses/by/4.0/). 